\title{
Ophthalmology Residents' Perspectives Regarding Disclosure of Resident Involvement in Ophthalmic Surgery
}

\author{
Ardalan Aminlari, $\mathrm{MD}^{1}$ Ingrid U. Scott, MD, $\mathrm{MPH}^{1,2}$ \\ ${ }^{1}$ Department of Ophthalmology, Penn State College of Medicine, \\ Hershey, Pennsylvania \\ 2 Department of Public Health Sciences, Penn State College of \\ Medicine, Hershey, Pennsylvania \\ ${ }^{3}$ Section of Ophthalmology, VA Medical Center, Providence, Rhode \\ Island \\ ${ }^{4}$ Division of Ophthalmology, Warren Alpert Medical School of Brown \\ University, Providence, Rhode Island
}

Journal of Academic Ophthalmology 2014;7:e3-e7.

\author{
Paul B. Greenberg, $\mathrm{MD}^{3,4}$
}

\begin{abstract}
Keywords

- resident surgery

- ophthalmic surgery

- disclosure of resident involvement

Objective To investigate ophthalmology residents' perspectives regarding disclosure to patients of resident involvement in surgery.

Methods An anonymous survey was constructed on http://www.surveymonkey.com. An email containing an explanation of the study, an invitation to residents to participate, and the survey link was sent to the coordinator of each ophthalmology residency program accredited by the Accreditation Council for Graduate Medical Education, and coordinators were asked to forward the email to all residents in their program.

Results Out of the 1,374 residents to whom the survey was sent, 262 (19.1\%) responded; $25.9 \%$ (66/262) of respondents reported their programs have an established policy regarding disclosure of resident involvement in surgery; $53.0 \%(35 / 66)$ of respondents at programs with an established disclosure policy identified the resident as having primary responsibility for disclosure, while $61.9 \%(117 / 189)$ of respondents at programs without an established disclosure policy indicated the attending physician should have primary responsibility for disclosure. Among respondents at programs with resident-run clinics, $87.8 \%(72 / 82)$ at programs with an established disclosure policy identified the resident as having primary responsibility of disclosure, and $62.0 \%$ (88) 141 ) at programs without an established disclosure policy reported the resident should be responsible for disclosure.

Conclusion A minority of ophthalmology residency programs employ policies for disclosure of resident involvement in surgery. There is a lack of consistency between respondents at programs with versus without an established disclosure policy regarding perceived responsibility for disclosure. Further research is warranted regarding the potential utility of a unified disclosure policy, and how different disclosure policies may affect patient consent for resident participation and resident surgical training opportunities.
\end{abstract}

\author{
Address for correspondence Ingrid U. Scott, MD, MPH, Department of \\ Ophthalmology, Penn State College of Medicine, 500 University Drive, \\ HU19, Hershey, PA 17033-0850 (e-mail: iscott@hmc.psu.edu).
}

DOI http://dx.doi.org/ 10.1055/s-0034-1396084. ISSN 2164-7879.
Copyright @ 2014 by Thieme Medical Publishers, Inc., 333 Seventh Avenue, New York, NY 10001, USA. Tel: +1(212) 584-4662.
License terms

(c) (1) $\ominus$ () 
In ophthalmology, as in other surgical specialties, there is a need to train surgeons comprehensively before entering practice. This presents a potential dilemma between providing optimal care for patients and providing training sufficient to prepare residents for comprehensive care. There is a frequently expressed concern among ophthalmologists and other surgeons that full disclosure of resident involvement in surgery may reduce patient consent for trainee participation in surgery and decrease surgical training opportunities for residents. ${ }^{1-3}$ Chen et al, ${ }^{4}$ in a recent survey of ophthalmology residency program directors (PDs) in the United States, underscored the paucity of data on current practices and policies regarding disclosure of resident involvement in ophthalmic surgery. The aim of the current study is to investigate ophthalmology residents' perspectives regarding disclosure of resident involvement in ophthalmic surgery.

\section{Methods}

Upon obtaining a study exemption from the Penn State College of Medicine Institutional Review Board, the FREIDA online database (http://www.ama-assn.org/go/frieda) was used to identify all ophthalmology residency programs accredited by the Accreditation Council for Graduate Medical Education (ACGME). Each program listing was reviewed to determine the number of residents at each program and to identify each program coordinator's contact information.

We developed an anonymous survey in multiple-choice and Likert-style format on the Web site http://www.surveymonkey.com (survey questions and statements, as well as response options, are displayed in - Tables 1 and $\mathbf{2}$ ). An email containing an explanation of the study, an invitation to residents to participate in the survey, and the link to the survey was sent to each program coordinator. The program coordinators were asked in the email, and in a subsequent phone call to each coordinator, to please forward the email to all of the ophthalmology residents in their program. We considered emailing PDs; however, after speaking with the ophthalmology residency PDs at several institutions, the consensus was that the most reliable and efficient way to have our survey reach the residents was through the program coordinators. Weekly reminders were sent to the program coordinators for the subsequent 3 weeks.

\section{Results}

Survey results are displayed in - Tables 1 and 2. Responses were received from $19.1 \%(262 / 1,374)$ of ophthalmology residents training at 117 ACGME-accredited ophthalmology programs in the United States. Sixty-six (25.9\%) of the respondents reported that their programs did have an established policy regarding disclosure of resident involvement in ophthalmic surgery. Of these 66 residents in programs with established policies, 35 (53.0\%) responded that the resident had the primary responsibility for informing patients about the level of resident involvement in surgery. Among the 189 residents at programs without an established policy, 117 (61.9\%) indicated that the attending physician should have the primary responsibility to inform patients about the level of resident involvement in surgery.

Two hundred twenty-nine respondents (90.2\%) reported that they attend a residency program that has a resident-run clinic (e.g., at a Veterans Administration [VA] Medical Center or a hospital). Among the respondents with a resident-run clinic, 141 (63.2\%) reported that their programs do not have an established policy regarding resident involvement in ophthalmic surgery. Of these 141 residents, 88 (62.0\%) reported that the resident should be responsible for the disclosure of resident involvement in surgery. Of the 82 residents from programs with resident-run clinics and established policies regarding resident involvement in ophthalmic surgery, $72(87.8 \%)$ responded that the resident has the primary responsibility of disclosure.

The majority of respondents (69.4\%; 168/242) believed that patients prefer to be asked permission in advance for a resident to participate in their ophthalmic care, and $69.3 \%$ (167/241) believe that patients prefer complete disclosure regarding the level of resident involvement. About half $(52.5 \% ; 127 / 242)$ of residents felt that disclosure of resident involvement reduces consent for resident involvement in surgery and decreases opportunities for resident surgical training. The majority (59.9\%; 145/242) of residents felt that disclosure of resident involvement increased patient anxiety levels. Approximately half (51.2\%; 124/242) of the residents felt that official guidelines from a professional organization (e.g., American Academy of Ophthalmology or ACGME) would assist in disclosing the level of resident involvement in ophthalmic surgery. The minority of respondents ( 24.8 and $31.1 \%$, respectively) considered medicolegal risk and insufficient time to be obstacles to disclosure.

\section{Discussion}

The results of this study suggest that only a few ophthalmology GME programs have established policies for the disclosure of resident involvement in surgery. To our knowledge, and based on a review of the Medline literature database, this is the first study that has sought to identify policies regarding primary responsibility for disclosure of resident involvement in surgical procedures.

In ophthalmology residency programs with established policies, slightly more than half of the responding residents indicated that residents have the primary responsibility of informing patients about the level of resident involvement in surgery. The majority of those without an established policy felt that the responsibility of disclosure belonged to the attending physician. The results of this study among ophthalmology residents, when compared with the results from the study among ophthalmology residency PDs, ${ }^{4}$ indicate the similarities between resident and PD responses in programs with established disclosure policies (53\% of residents and 54\% of PDs believe that the primary responsibility of disclosure of resident participation in surgery lies with residents). When comparing the results of respondents at programs without an established policy, the majority of residents (61.9\%) and PDs ( $80 \%$ ) believe that the attending physician should have the 
Table 1 Residents' perspectives of responsibility regarding disclosure of resident involvement in ophthalmic surgery

\begin{tabular}{|c|c|c|c|}
\hline Question number & Question & Respondents, no. (\%) & Response count \\
\hline \multirow[t]{4}{*}{1} & What is your current level of training? & & 262 \\
\hline & PGY2 & $98(37.4)$ & \\
\hline & PGY3 & $79(30.2)$ & \\
\hline & PGY4 & $85(32.4)$ & \\
\hline \multirow[t]{3}{*}{2} & $\begin{array}{l}\text { Does your program have an established policy } \\
\text { on disclosing the level of resident involvement } \\
\text { to patients undergoing ophthalmic surgery? }\end{array}$ & & 254 \\
\hline & Yes & $66(25.9)$ & \\
\hline & No & $188(74.0)$ & \\
\hline \multirow[t]{5}{*}{$2 a$} & $\begin{array}{l}\text { If yes, who has the primary responsibility for } \\
\text { informing the patient about the level of resi- } \\
\text { dent involvement in ophthalmic surgery? }\end{array}$ & & 66 \\
\hline & Attending physician & 31 (46.9) & \\
\hline & Resident physician & $35(53.0)$ & \\
\hline & Nurse & 0 & \\
\hline & Other & 0 & \\
\hline \multirow[t]{5}{*}{$2 b$} & $\begin{array}{l}\text { If no, who should have the primary responsi- } \\
\text { bility for informing the patient about the level } \\
\text { of resident involvement in ophthalmic surgery? }\end{array}$ & & 189 \\
\hline & Attending physician & $117(61.9)$ & \\
\hline & Resident physician & $70(37.0)$ & \\
\hline & Nurse & 0 & \\
\hline & Other & $2(1.1)$ & \\
\hline \multirow[t]{3}{*}{3} & $\begin{array}{l}\text { Does your program have a resident-run clinic } \\
\text { (VA or hospital)? }\end{array}$ & & 254 \\
\hline & Yes & $229(90.2)$ & \\
\hline & No & $25(9.8)$ & \\
\hline \multirow[t]{3}{*}{$3 a$} & $\begin{array}{l}\text { If yes, does your resident-run clinic (VA or } \\
\text { hospital) have an established policy on dis- } \\
\text { closing the level of resident involvement to } \\
\text { patients undergoing ophthalmic surgery? }\end{array}$ & & 223 \\
\hline & Yes & $82(36.8)$ & \\
\hline & No & $141(63.2)$ & \\
\hline \multirow[t]{5}{*}{$3 b$} & $\begin{array}{l}\text { If yes, who has the primary responsibility for } \\
\text { informing the patient about the level of } \\
\text { resident involvement in ophthalmic surgery at } \\
\text { the resident-run clinic? }\end{array}$ & & 82 \\
\hline & Attending physician & $10(12.2)$ & \\
\hline & Resident physician & $72(87.8)$ & \\
\hline & Nurse & 0 & \\
\hline & Other & 0 & \\
\hline \multirow[t]{5}{*}{$3 c$} & $\begin{array}{l}\text { If no, who should have the primary responsi- } \\
\text { bility for informing the patient about the level } \\
\text { of resident involvement in ophthalmic surgery? }\end{array}$ & & 142 \\
\hline & Attending physician & $54(38.0)$ & \\
\hline & Resident physician & $88(62.0)$ & \\
\hline & Nurse & 0 & \\
\hline & Other & 0 & \\
\hline
\end{tabular}


Table 2 Residents' perspectives regarding disclosure policies

\begin{tabular}{|l|l|l|l|l|}
\hline Survey statement & $\begin{array}{l}\text { Strongly agree or } \\
\text { agree (\%) }\end{array}$ & $\begin{array}{l}\text { Neither agree } \\
\text { nor disagree }\end{array}$ & $\begin{array}{l}\text { Disagree or } \\
\text { strongly disagree }\end{array}$ & Response count \\
\hline $\begin{array}{l}\text { Patients prefer to be asked permission in } \\
\text { advance for a resident to participate in their } \\
\text { ophthalmic surgery }\end{array}$ & $168(69.4)$ & 51 & 23 & 242 \\
\hline $\begin{array}{l}\text { Patients prefer complete disclosure regarding } \\
\text { the level of resident involvement in their } \\
\text { ophthalmic surgery }\end{array}$ & $167(69.2)$ & 50 & 24 & 241 \\
\hline $\begin{array}{l}\text { Disclosure of the level of resident involvement } \\
\text { in their ophthalmic surgery increases a } \\
\text { patient's anxiety level }\end{array}$ & $145(59.9)$ & 55 & 42 & 242 \\
\hline $\begin{array}{l}\text { Disclosure of the level of resident involvement } \\
\text { in ophthalmic surgery reduces consent for } \\
\text { resident participation and decreases } \\
\text { opportunities for resident surgical training }\end{array}$ & $127(52.4)$ & 55 & 60 & 242 \\
\hline $\begin{array}{l}\text { Disclosure of the level of resident involvement } \\
\text { in ophthalmic surgery increases the attending } \\
\text { surgeon's medicolegal risk }\end{array}$ & $60(24.8)$ & 65 & 116 & 241 \\
\hline $\begin{array}{l}\text { Official guidelines from a professional organi- } \\
\text { zation (e.g., American Academy of Ophthal- } \\
\text { mology or AcGME) would assist in disclosing } \\
\text { the level of resident involvement in ophthalmic } \\
\text { surgery }\end{array}$ & $124(51.2)$ & 65 & 53 & 242 \\
\hline $\begin{array}{l}\text { There is often insufficient time to talk to } \\
\text { patients about the level of resident involvement } \\
\text { in their ophthalmic surgery }\end{array}$ & $75(31.1)$ & 56 & 110 & 241 \\
\hline
\end{tabular}

primary responsibility to inform patients about resident involvement. These results suggest that there is a general lack of consistency between respondents at programs with versus without an established disclosure policy regarding perceived responsibility for disclosure of resident participation in ophthalmic surgery and underscore the need for further research regarding the potential utility of a unified disclosure policy.

Among resident respondents at programs with residentrun clinics (VA or hospital), most felt that the resident had the responsibility of disclosing to patients the level of resident involvement in surgery. Perhaps in resident-run clinics, as opposed to faculty practices, the resident is perceived to function as the "attending" and, therefore, to have the primary responsibility of disclosure.

Perceived barriers to disclosure include patient anxiety and potential loss of resident surgical cases. A minority of respondents considered medicolegal and insufficient time for disclosure obstacles to disclosure. In a study by Nguyen and colleagues, ${ }^{5} 20$ ophthalmologists were asked if they would use a standardized form that disclosed resident involvement in cataract surgery. The acceptance rate was poor, with only five agreeing to such a form. The 15 who did not agree cited perceived barriers to disclosure similar to those identified in the current study, such as patient anxiety, potential loss of surgical cases and length of time needed to discuss the resident involvement.

The current study is limited by the survey response rate of $19 \%$, which may limit the generalizability of the results.
However, this rate is comparable to the response rate of $23 \%$ in a recent survey of U.S. ophthalmology residents. ${ }^{6}$ In addition, the multiple-choice format of the survey may have caused bias and prevented us from uncovering other potential barriers to disclosure.

To our knowledge, there is no publically available primer for steps in disclosing resident involvement in ophthalmic surgery. The "Informed Consent" section of the Code of Ethics of the American Academy of Ophthalmology (AAO) states only that "the performance of medical or surgical procedures shall be preceded by appropriate informed consent." In the "Communication with the Patient" section of the AAO's Code of Ethics, it states that "open communication with the patient is essential."

The current study suggests a lack of a general policy regarding disclosure of resident involvement in ophthalmic surgery and a lack of consistency between respondents at programs with versus without an established disclosure policy regarding perceived responsibility for such disclosure. This study also suggests that such a policy might be welcome among ophthalmology residents. Further research is warranted to determine how different disclosure policies may affect patient consent for resident participation and resident surgical training opportunities.

\section{Disclaimer}

The views expressed in this article are those of the authors and do not necessarily reflect the position or policy of the U.S. Department of Veterans Affairs or the U.S. government. 


\section{References}

1 Wisner DM, Quillen DA, Benderson DM, Green MJ. Patient attitudes toward resident involvement in cataract surgery. Arch Ophthalmol 2008;126(9):1235-1239

2 Vallance JH, Ahmed M, Dhillon B. Cataract surgery and consent; recall, anxiety, and attitude toward trainee surgeons preoperatively and postoperatively. J Cataract Refract Surg 2004;30(7):1479-1485

3 Scott IU, Smalley AD, Kunselman AR. Ophthalmology residency program leadership expectations of resident competency in retinal procedures and resident experience with retinal procedures. Retina 2009;29(2):251-256
4 Chen AJ, Scott IU, Greenberg PB. Disclosure of resident involvement in ophthalmic surgery. Arch Ophthalmol 2012;130(7): 932-934

5 Nguyen TN, Silver D, Arthurs B. Consent to cataract surgery performed by residents. Can J Ophthalmol 2005;40(1):34-37

6 Hasan SJ, Castanes MS, Coats DK. A survey of ophthalmology residents' attitudes toward pediatric ophthalmology. J Pediatr Ophthalmol Strabismus 2009;46(1):25-29

7 American Academy of Ophthalmology Code of Ethics. Available at: http://www.aao.org/about/ethics/code_ethics.cfm. Accessed February 20, 2013 